\title{
Diagnostic and Anatomical Studies on Unilateral Hydronephrosis in Domestic Cats
}

\section{Hitham Abdel-Saeed ${ }^{1}$, Reem R. Tahon ${ }^{2 *}$, Mohamed E. Ali ${ }^{1}$ \\ ${ }^{1}$ Department of Medicine, Faculty of Veterinary Medicine, Cairo University, Egypt; ${ }^{2}$ Department of Anatomy and Embryology, Faculty of Veterinary Medicine, Cairo University, Egypt.}

\begin{abstract}
Feline unilateral hydronephrosis is a critical disease in cat medicine. Twenty-six domestic cats from the teaching veterinary hospital and private clinics in Egypt were used in this study. For the diagnostic study, we examined twelve healthy cats and nine cats suffering from unilateral hydronephrosis. Diagnosis included physical examination, laboratory analysis, and ultrasonographical and radiographical examinations. In physical examinations of diseased cases, the respiration rate was increased, anemia, pale mucous membrane, and pollakiuria. In hematological parameters, significant decrease in packed cell volume (PCV), hemoglobin concentration, and Red blood cells (RBCs) count, while white blood cells (WBCs) and absolute neutrophilic count were increased. Radiopaque renal calculi appeared radiologically in some cases. Ultrasonographically, an increase in the length of the kidney and severe enlargement with loss of architecture of renal parenchyma and also severely enlarged renal pelvises were gathered. For the anatomical study, seven cases (two of them were in common with diagnostic examination) were dissected. Kidney were smooth unipapillated with the right kidney positioned more cranial than the left one. Radiologically, both kidneys might appear mostly overlapping each other also the radiological length of the healthy kidney was 3 times the length of the second lumbar vertebra (L2) while the length of the hydronephrotic kidney reached 3.5 times the length of L2. The normal and hydronephrotic renal anatomical measurements were included. We concluded that not only the increase in kidney size indicated unilateral hydronephrosis but also loss of renal parenchymal architecture ultrasonographically and anatomically an increase in renal pelvis width in addition to significant changes in biochemical parameters.
\end{abstract}

Keywords | Kidney, Cat, Unilateral hydronephrosis, Anatomy, Diagnosis

Received | June 16, 2021; Accepted | July 12, 2021; Published | August 25, 2021

*Correspondence | Reem R. Tahon, Department of Medicine, Faculty of Veterinary Medicine, Cairo University, Egypt; Email: reemtahon@gmail.com Citation | Abdel-Saeed H, Reem RT, Ali ME (2021). Diagnostic and anatomical studies on unilateral hydronephrosis in domestic cats. Adv. Anim. Vet. Sci. 9(10): 1641-1648.

DOI | http://dx.doi.org/10.17582/journal.aavs/2021/9.10.1641.1648

ISSN (Online) | 2307-8316; ISSN (Print) | 2309-3331

Copyright (C) 2021 Abdel-Saeed et al. This is an open access article distributed under the Creative Commons Attribution License, which permits unrestricted use, distribution, and reproduction in any medium, provided the original work is properly cited.

\section{INTRODUCTION}

$\mathrm{F}$ eline hydronephrosis is a common disease in feline practice that possessed challenging criteria for most practitioners, unilateral hydronephrosis is associated with silent symptoms and is difficult to be identified by the owner which is the main problem leading to dysfunction of other organs or death of the diseased cat. Most of the revealing studies mentioned that the increase in the size of the kidney was the main criteria of unilateral hydronephrosis but we proved that normal-sized kidneys suffered from unilateral hydronephrosis so that the main criteria in our studies are the loss of architecture of the kidney and increased renal pelvis width. Also, the previous studies revealed that there were no changes in biochemical parameter but we detected that those parameters were increased. Unilateral hydronephrosis may be caused by congenital ureteral stricture, adhesions after surgery, accidents, and obstruction by calculi. For the diagnosis of unilateral hydronephrosis; abdominal palpation is considereda standard in preliminary diagnostic steps, integration between hematobiochemical procedures, radiography, and ultrasonography is needed for achieving an accurate diagnosis. The feline kidneys were retroperitoneal 
organs adjacent to the sublumbar muscles on either side of the abdominal aorta and caudal vena cava (Aronson, 2013). The previous literatures lack the anatomical measurements of unilateral hydronephrotic kidney in addition to the changes in the kidney macrostructure. The anatomical kidney measurements of both healthy and hydronephrotic kidneys were a basic study for the clinician to differentiate the healthy kidney and the enlarged one. In our study, the renal pelvis was mostly affected in the hydronephrotic kidney to be extremely dilated at the expense of the renal cortex and medulla thickness to reach in progressive stages to be membranous kidney from extreme enlargement.

\section{MATERIALS AND METHODS}

The institutional animal care and use committee (IACUC) approval number was: Vet CU24112020258. Twenty-six domestic cats of both sexes with a weight range of 3-5 kg were randomly selected and studied. For the diagnostic studies; twelve healthy cats and nine cats suffering from unilateral hydronephrosis were examined, where two cat cases of the diseased group were studied anatomically for the kidney macro changes while another five healthy cats were used for anatomical dissection. The cats used for this study were collected from the teaching veterinary hospital, faculty of veterinary medicine, Cairo University, Giza, Egypt, also from private clinics.

Clinical examinations included complete medical, vaccination, dietary, management, and environmental history. Physical examinations included respiration; pulse rates and rectal temperature were recorded.

Laboratory analysis incorporated complete blood count $(\mathrm{CBC})$, Estimation of biochemical blood constituents was applied comprising serum BUN and creatinine using specific kits supplied by Spectrum diagnostic Co. (MDSS, GmbH, Germany). Serum sodium concentration was established with specific kits supplied by Stanbio Laboratories, USA, while serum potassium by kits supplied by QCA Co., Spain.

Ultrasound examination was applied using an ultrasonographic device (Pie medical ${ }^{\oplus}$ ) scanner, Netherlands with micro convex sector transducers 5-7.5 $\mathrm{MHz}$. The radiographical examination was applied using an X-ray machine (Fisher imaging ${ }^{\circledR}$ ).

The anatomical study used seven domestic cats for dissection and cast of the blood vessels and also the diseased cats with unilateral hydronephrosis. Five cats were used for the kidney morphology and blood supply studies, those cats were anesthetized with xylazine $1 \mathrm{mg} / \mathrm{Kg} / \mathrm{IM}$ and ketamine $20 \mathrm{mg} / \mathrm{Kg} / \mathrm{IM}$. After muscular relaxation, they sacrificed using injection of sodium thiopental at $2.5 \%$ in the lethal doses of $60 \mathrm{mg} / \mathrm{Kg} / \mathrm{IV}$. Fresh dissection and cast for the blood supply and venous drainage was applied. Three cats were dissected freshly for kidney morphology in situ then separated and further dissection occurred then fixed by $10 \%$ formalin. Two cats were injected with colored blue and red latex neoprene into the caudal vena cava and abdominal aorta respectively, and then fixed by freezing overnight.

Two diseased kidneys with unilateral hydronephrosis were collected in pet clinics, one from a cat died in an accident and the other was collected after unilateral nephrectomy. All figures were photographed by sony camera h400,20.1 megapixels, 63X optical zoom cyber shot.

\section{STATISTICAL ANALYSiS}

All data about clinical examinations, haemato-biochemical findings, ultrasonographic and anatomical measurements were recorded, imported to a Microsoft Excel 2010 spreadsheet. The t-test was applied using SPSS program version 2016, P-value $\leq 0.05$ was considered significant according to Levesque (2007).

\section{RESULTS AND DISCUSSION}

\section{Diagnostic STUdy}

\section{Physical examination}

The main recorded clinical signs were pale mucous membranes, Anorexia, weight loss, Pollakiuria and hematuria. Abdominal palpation had a significant role in diagnosis through detection of one enlarged kidney and the other was normal size.

Regarding physical examination parameters and in the light of statistical analysis (Table 1), results showed a significant $(\mathrm{P} \leq 0.05)$ increase in the respiration rate in diseased cats compared with healthy cats. Both pulse rate and rectal temperature showed a non-significant increase among diseased cats.

\section{Hematobiochemical parameters}

Statistical analysis of the hematological parameters (Table 1) showed a significant decrease in $P C V \quad(P \leq 0.001)$, hemoglobin concentration $(\mathrm{P} \leq 0.01)$, and $\mathrm{RBC}$ s count $(\mathrm{P} \leq 0.05)$ in diseased cats in comparison with healthy cats. In the terms of WBCs count and absolute neutrophilic count, statistics revealed a significant $(\mathrm{P} \leq 0.001)$ increase in both counts in diseased cats compared with the healthy group. Red cell indices including mean corpuscular volume (MCV), mean corpuscular hemoglobin $(\mathrm{MCH})$ and mean corpuscular hemoglobin concentration (MCHC) showed a non-significant decrease in diseased cats.

In the term of serum biochemical parameters, statistical 
OPEN OACCESS

analysis results (Table 1$)$ recorded significant $(\mathrm{P} \leq 0.001)$ increase in BUN level. Also, a significant increase $(\mathrm{P} \leq 0.01)$ was recorded for serum creatinine level. Both sodium and potassium levels showed mild non-significant elevation among diseased cats compared with healthy cats.

\section{RADIOGRAPHIC \\ AND \\ ULTRASONOGRAPHIC} EXAMINATIONS

Radiographic examinations (Figure 1) revealed the presence of radio-opaque left renal calculi in two cases, where one of them suffered from marked enlargement of the left kidney.

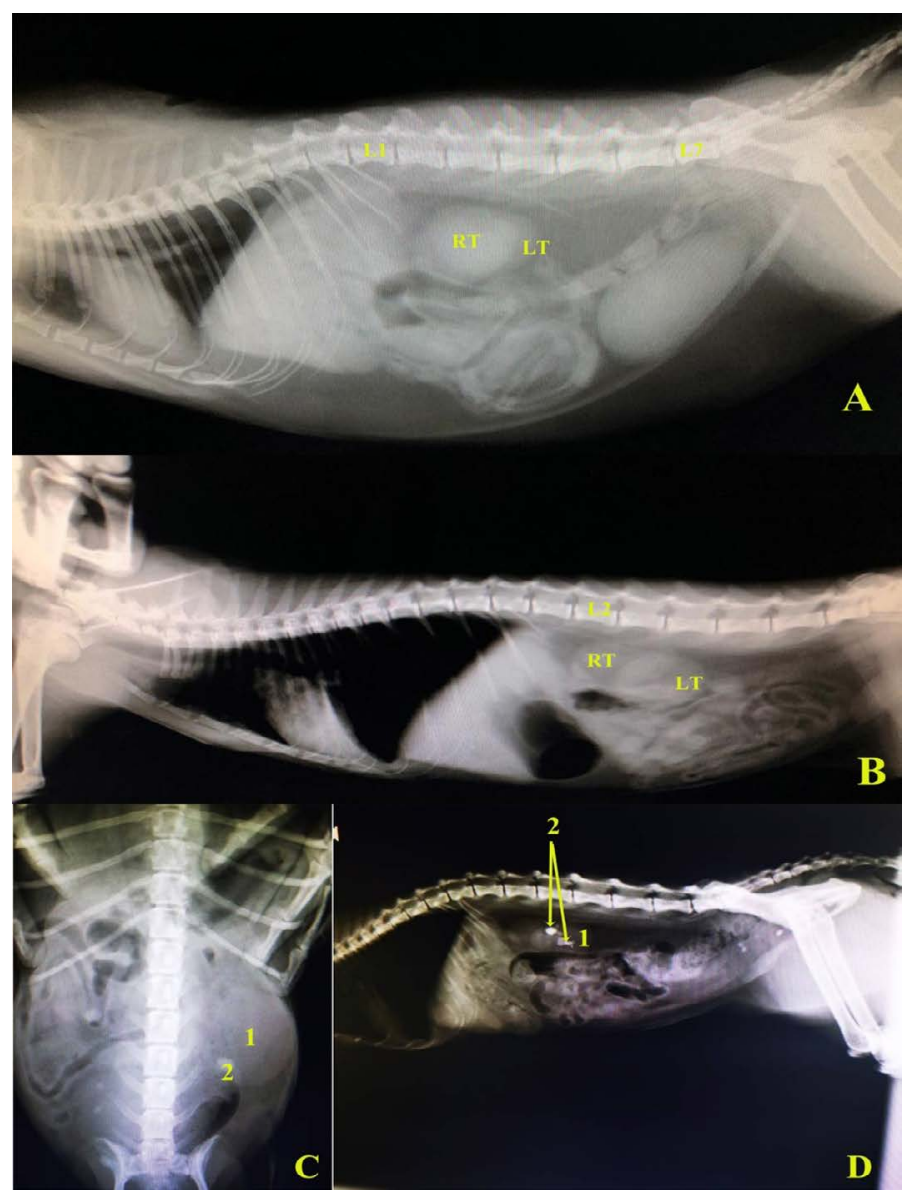

Figure 1: $\mathrm{A}$ and $\mathrm{B}$, left lateral radiographic view in two domestic cats showing the normal positions of right and left kidneys. C, Ventrodorsal radiographic view showing enlarged left kidney (hydronephrosis), D, left lateral radiographic view showing renal calculi in left kidney, in domestic cats. L1.1 ${ }^{\text {st }}$ lumber vertebra, L2.2 $2^{\text {nd }}$ lumber vertebra, L7. $7^{\text {th }}$ lumber vertebra, RT right kidney, LT.left kidney, 1 left kidney (hydronephrotic in C), 2. Renal calculus.

Statistical ultrasonographical measurements (Table 2) were analyzed in both kidneys in healthy cats as mean \pm standard error. In diseased cats with unilateral Hydronephrosis (Figure 2), two cases showed an increase in the length of the right kidney (measured length: 5.5 and $4.44 \mathrm{~cm}$ ). Three cases showed severe enlargement in one kidney with loss of the criteria and architecture of renal parenchyma. One diseased case showed normal length and width of affected left kidney with loss of architecture of renal parenchyma. Also, marked thinning of both renal cortex and medulla were evident as a result of pressure made by the severely enlarged renal pelvis.

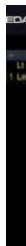
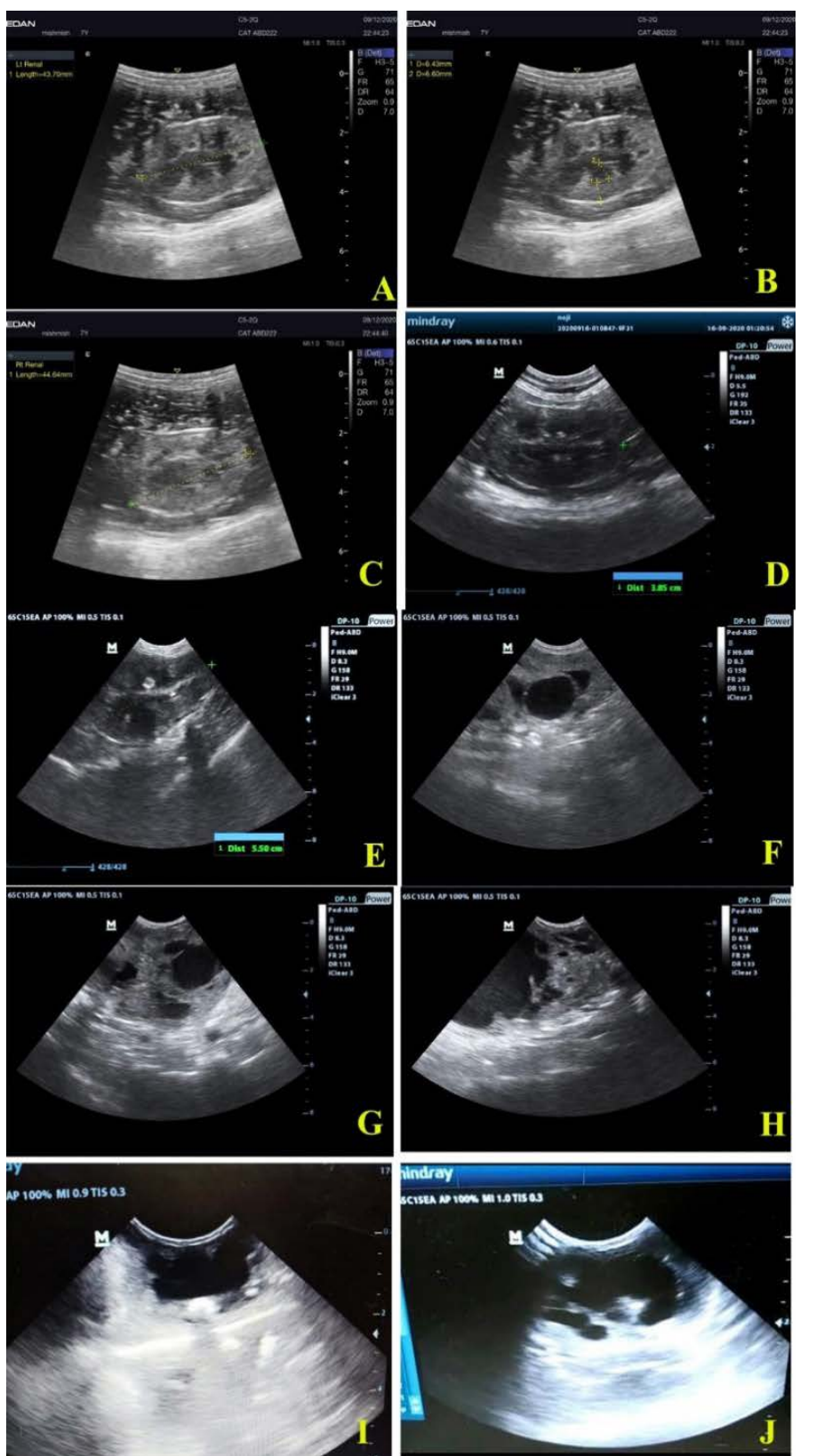

Figure 2: Ultrasonographic views of healthy feline kidneys showing. A, Left kidney with length $4.37 \mathrm{~cm}$; B, left renal cortex $(0.64 \mathrm{~cm})$, renal medulla $(0.66 \mathrm{~cm}) ; \mathrm{C}$, right kidney length $4.46 \mathrm{~cm}$; D, left kidney of another cat with length $3.85 \mathrm{~cm}$. Feline unilateral hydronephrosis cases showing; E, enlarged right kidney ( $5.50 \mathrm{~cm}$ length); F, loss of architecture and dilated renal pelvis of right kidney in two years old mixed breed tomcat; $\mathrm{G}$ and $\mathrm{H}$, loss of echotexture with multiple diverticuli in right kidney of 1 year old mixed breed queen; I, severe dilation of renal pelvis with thinning of renal cortex and medulla; J, massive loss of architecture with normal dimensional left kidney in 3 months old tomcat. 
Table 1: Physical and hematobiochemical parameters cats suffered from unilateral Hydronephrosis.

\begin{tabular}{|c|c|c|c|}
\hline \multicolumn{2}{|l|}{ Parameter group } & Control group & Hydronephrosis (unilateral) \\
\hline \multirow[t]{3}{*}{ Physical parameters } & Respiration rate (Time/min) & $40 \pm 1.04$ & $45 \pm 2.9^{*}$ \\
\hline & Pulse rate (Pulse/min) & $129 \pm 4.28$ & $136 \pm 5.86$ \\
\hline & Rectal temperature $\left({ }^{\circ} \mathrm{C}\right)$ & $38.4 \pm 0.05$ & $38.6 \pm 0.10$ \\
\hline \multirow{12}{*}{$\begin{array}{l}\text { Hematological } \\
\text { parameters }\end{array}$} & $\operatorname{PCV}(\%)$ & $38.9 \pm 0.67$ & $33 \pm 1.46^{* * *}$ \\
\hline & $\mathrm{Hb}(\mathrm{g} / \mathrm{dl})$ & $10.6 \pm 0.32$ & $8.7 \pm 0.50^{* *}$ \\
\hline & RBCs count $\left(\times 10^{6} / \mu \mathrm{l}\right)$ & $8.22 \pm 0.18$ & $7.34 \pm 0.32^{*}$ \\
\hline & $\mathrm{MCV}(\mathrm{Fl})$ & $47.6 \pm 1.02$ & $45.6 \pm 3.34$ \\
\hline & $\mathrm{MCH}(\mathrm{Pg} / \mathrm{l})$ & $12.9 \pm 0.21$ & $12 \pm 0.68$ \\
\hline & $\mathrm{MCHC}(\%)$ & $27.3 \pm 0.66$ & $27.1 \pm 2.44$ \\
\hline & WBCs count $\left(\times 10^{3} / \mu \mathrm{l}\right)$ & $11.08 \pm 0.32$ & $16.49 \pm 1.82^{* * *}$ \\
\hline & Absolute neutrophils (cell/ $\mu \mathrm{l})$ & $7435 \pm 297$ & $13114 \pm 1907^{* * *}$ \\
\hline & Absolute lymphocytes (cell/ $\mu \mathrm{l})$ & $2985 \pm 189$ & $2714 \pm 216$ \\
\hline & Absolute monocytes (cel1/ $/ \mathrm{l})$ & $537 \pm 24.2$ & $547 \pm 64$ \\
\hline & Absolute eosinophils (cell/ $/ \mu \mathrm{l})$ & $123 \pm 11.9$ & $117 \pm 24$ \\
\hline & 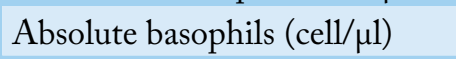 & 0.00 & $0.14 \pm 0.14$ \\
\hline \multirow{4}{*}{$\begin{array}{l}\text { Biochemical } \\
\text { parameters }\end{array}$} & BUN (mg/dl) & $30 \pm 0.90$ & $44.5 \pm 2.67^{* * *}$ \\
\hline & Creatinine (mg/dl) & $1.5 \pm 0.06$ & $2 \pm 0.18^{* *}$ \\
\hline & Sodium (mmol/l) & $147.8 \pm 1.76$ & $149.2 \pm 4.47$ \\
\hline & Potassium (mmol/1) & $4.6 \pm 0.10$ & $4.8 \pm 0.30$ \\
\hline
\end{tabular}

Table 2: Renal ultrasonographic measurements (mean \pm standard error) of both kidneys in healthy cats.

$\begin{array}{lll}\text { Parameters } & \text { Right kidney } & \text { Left kidney } \\ \text { Length }(\mathrm{cm}) & 4.20 \pm 0.14 & 4.10 \pm 0.15 \\ \text { Width }(\mathrm{cm}) & 2.42 \pm 0.09 & 2.36 \pm 0.10 \\ \text { Cortex }(\mathrm{cm}) & 0.60 \pm 0.02 & 0.58 \pm 0.02 \\ \text { Medulla }(\mathrm{cm}) & 0.61 \pm 0.02 & 0.61 \pm 0.02\end{array}$

\section{AnATOMicAl STUDY}

Kidneys of domestic cats were small bean shape with rounded poles (Figure 3E and 3F), light brown color, smooth unipapillated with no difference in shape between right and left. They were sublumbar and retroperitoneal organs caudal to the rib cage, with a flat dorsal surface and convex ventral surface (Figure $4 \mathrm{~A}$ and $4 \mathrm{~B}$ ). The anterior pole of the right kidney was related to the caudate lobe of the liver (Figure 3E) by the hepatorenal ligament. The left kidney was caudal to the spleen, also it was movable. The caudal part only of right kidney could be physically palpated due to its relation with the liver. On the other hand, the poles of the left kidney could be palpated physically.

The right kidney extended ventral to L2 -L4 while the left kidney extended from L3-L4 so that the right kidney was situated more cranial than the left one. Also, they might appear on X-rays to be mostly overlapping each other. The healthy kidney of the cat was 3.0 the length of L2 while the hydronephrotic kidney reached 3.5 the length of L2 (Figure 1C).

\section{INTERNAL STRUCTURE OF KIDNEY}

The renal fibrous capsule was surrounding the whole kidney containing capsular veins and loosely attached to the renal cortex except in affected areas of the kidney (Figure 3D blue arrows) where adhesions occur. The renal cortex was light brown; its length was about $0.60 \pm 0.02$ and $0.60 \pm 0.01 \mathrm{~cm}$ in right and left kidneys, respectively. Capsular veins (Figure 5D) appeared in shallow grooves on the external surface of the renal cortex, while in the sagittal section, the interlobular arteries and veins were viewed. The renal medulla (Figure 4) was divided into outer dark red and inner pale red in the sagittal section. Moreover, six dark red renal pyramids appear in the sagittal section which was divided by renal columns at the base of the pyramid. The inner medulla formed a crest leading to the renal pelvis which was a simple funnel shape in the middle part of the medial border with collateral recesses (Figure 4F) collecting the urine to the renal crest. The renal hilus was a depressed medial area, leading internally to the renal sinus.

\section{RENAL ANATOMICAL MEASUREMENTS}

Renal anatomical measurements (Table 3) included the length of healthy right kidney of the cat was $4.21 \pm 0.05$ $\mathrm{cm}$ and the left kidney was $4.08 \pm 0.04 \mathrm{~cm}$ the width of the right and left kidneys were $2.41 \pm 0.05$ and $2.70 \pm 0.02$ $\mathrm{cm}$ respectively. In the case of hydronephrosis, the length of left kidney increased to reach $4.8 \pm 0.63 \mathrm{~cm}$ or more due to the increase in renal pelvis width $2.3 \pm 0.37 \mathrm{~cm}$. In one case of unilateral hydronephrosis we gathered that the 
total length of the kidney was normal but the renal pelvis width is increased (Figure 4G) while the renal cortex and medulla thickness were decreased.
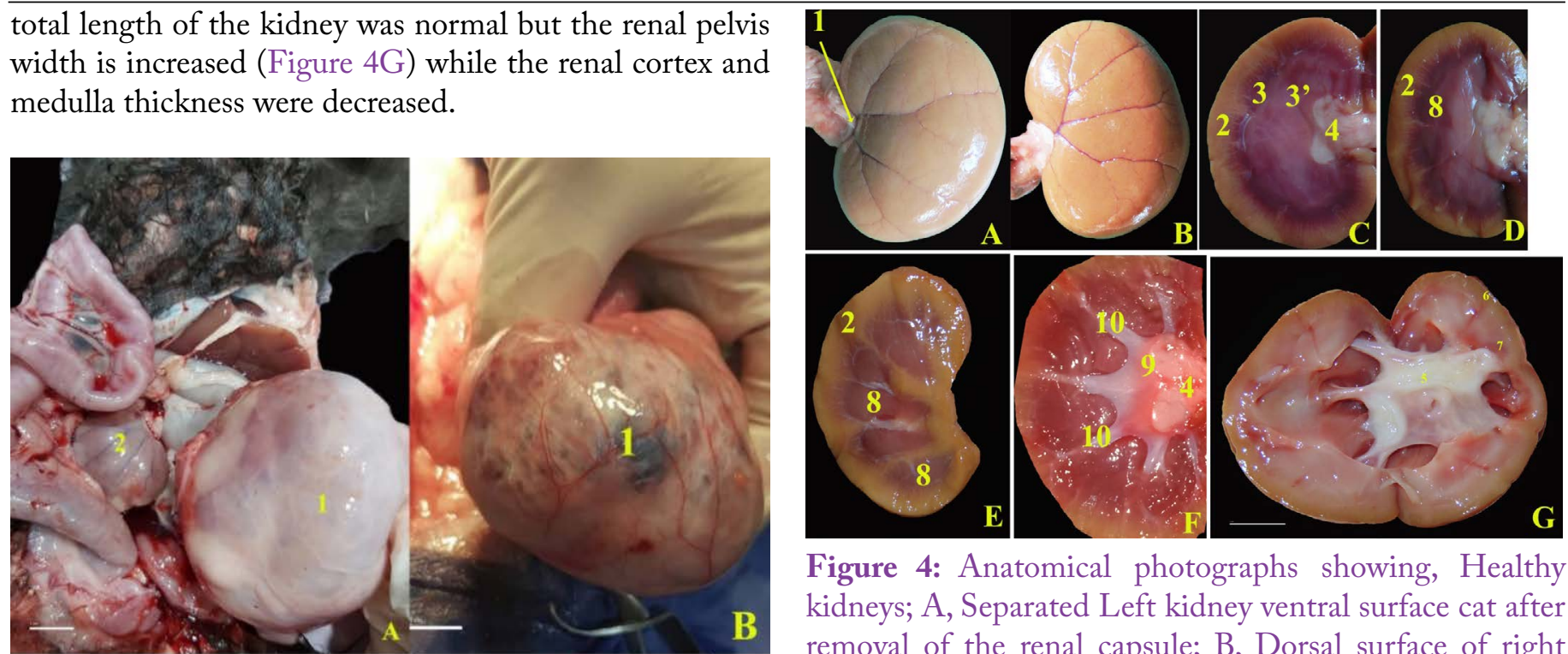

Figure 4: Anatomical photographs showing, Healthy kidneys; A, Separated Left kidney ventral surface cat after removal of the renal capsule; $\mathrm{B}$, Dorsal surface of right kidney; $\mathrm{C}$, the mid sagittal section; $\mathrm{D}$, parasagittal section; $\mathrm{E}$ and $\mathrm{F}$, sagittal sections. In diseased cat; D, midsagittal section of left hydronephrotic kidney with normal size. 1 , renal hilus; 2 , renal cortex; 3 , outer renal medulla; 3 , inner renal medulla; 4, normal renal pelvis; 5, Dilated renal pelvis due to hydronephrosis; 6, Renal cortex reduced in thickness; 7, Renal medulla reduced in thickness; 8, renal pyramid; 9 , renal crest; 10 , collateral recesses.

Table 3: Renal anatomical measurements (mean \pm standard error) in fresh specimen of healthy and diseased cats (unilateral Hydronephrosis).

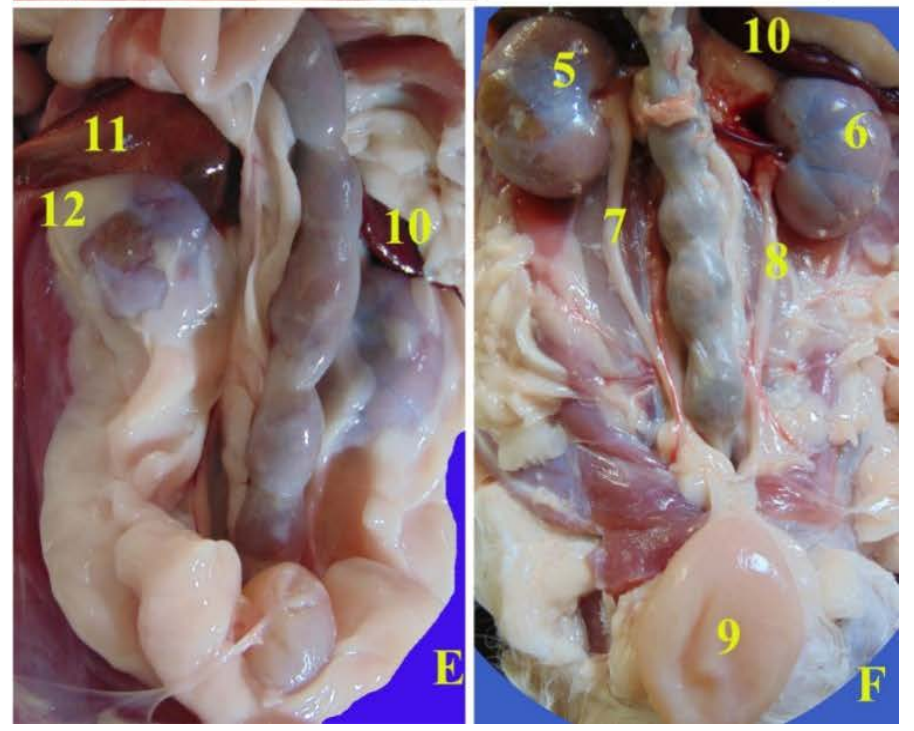

Figure 3: Unilateral hydronephrotic kidneys collected from two cases. A and B, the right kidney extremly enlarged; C and $\mathrm{D}$, the hydronephrotic left kidney was collected after nephroctomy surgery. In healthy cats, E, F, Anatomical photographs of the ventrodorsal view of the abdominal cavity of healthy domestic cat, B, after removal of the perirenal fat. 1, Right hydronephrotic kidney; 2, Left small kidney; 3, left hydronephrotic kidney; 4, Adhesions in the renal capsule to the renal cortex of hydronephrotic kidney; 5, right kidney; 6, left kidney; 7, right ureter; 8, left ureter; 9 , urinary bladder; 10 , spleen; 11 , caudate lobe; 12 , capsula adiposa.

\begin{tabular}{llll} 
Parameters & $\begin{array}{l}\text { Right } \\
\text { kidney }\end{array}$ & Left kidney & $\begin{array}{l}\text { Hydronephrotic } \\
\text { left kidney }\end{array}$ \\
\hline Length $(\mathrm{cm})$ & $4.21 \pm 0.05$ & $4.08 \pm 0.04$ & $4.8 \pm 0.63$ \\
\hline Width $(\mathrm{cm})$ & $2.41 \pm 0.05$ & $2.70 \pm 0.02$ & $3.2 \pm 0.26^{* *}$ \\
\hline $\begin{array}{l}\text { Thickness }(\mathrm{cm}) \\
\text { Cortex }(\mathrm{cm})\end{array}$ & $1.5 \pm 0.03$ & $1.60 \pm 0.02$ & $2 \pm 0.43$ \\
Medulla $(\mathrm{cm})$ & $1.31 \pm 0.02$ & $1.42 \pm 0.02$ & $0.6 \pm 0.05^{* * *}$ \\
\hline $\begin{array}{l}\text { Renal pelvis }(\mathrm{cm}) \\
0.9 \pm 0.01\end{array}$ & $1.01 \pm 0.03$ & $2.3 \pm 0.37^{* * *}$ \\
$\begin{array}{l}\text { Renal artery } \\
\text { length }(\mathrm{cm})\end{array}$ & $2.71 \pm 0.06$ & $2.34 \pm 0.05$ & -- \\
\hline $\begin{array}{l}\text { Renal vein length } \\
(\mathrm{cm})\end{array}$ & $2.41 \pm 0.03$ & $3.11 \pm 0.03$ & -- \\
\hline
\end{tabular}

**** $\mathrm{p} \leq 0.001 \quad$ (high significance) and ${ }^{* *} \mathrm{p} \leq 0.01 \quad$ (moderate significance).

In physical examination, a significant increase in respiration rate came in the same context of Abdel-Saeed et al. (2020) who recorded a positive correlation between the increase in the level of BUN, acidosis, and increased respiration rate. In agreement with Segev (2011), there was a big kidney and small kidney syndrome for such cases. Also, Ragni and Fews (2008) recorded the presence of mass at the craniodorsal aspect of the abdomen with pain in cases with unilateral Hydronephrosis. 


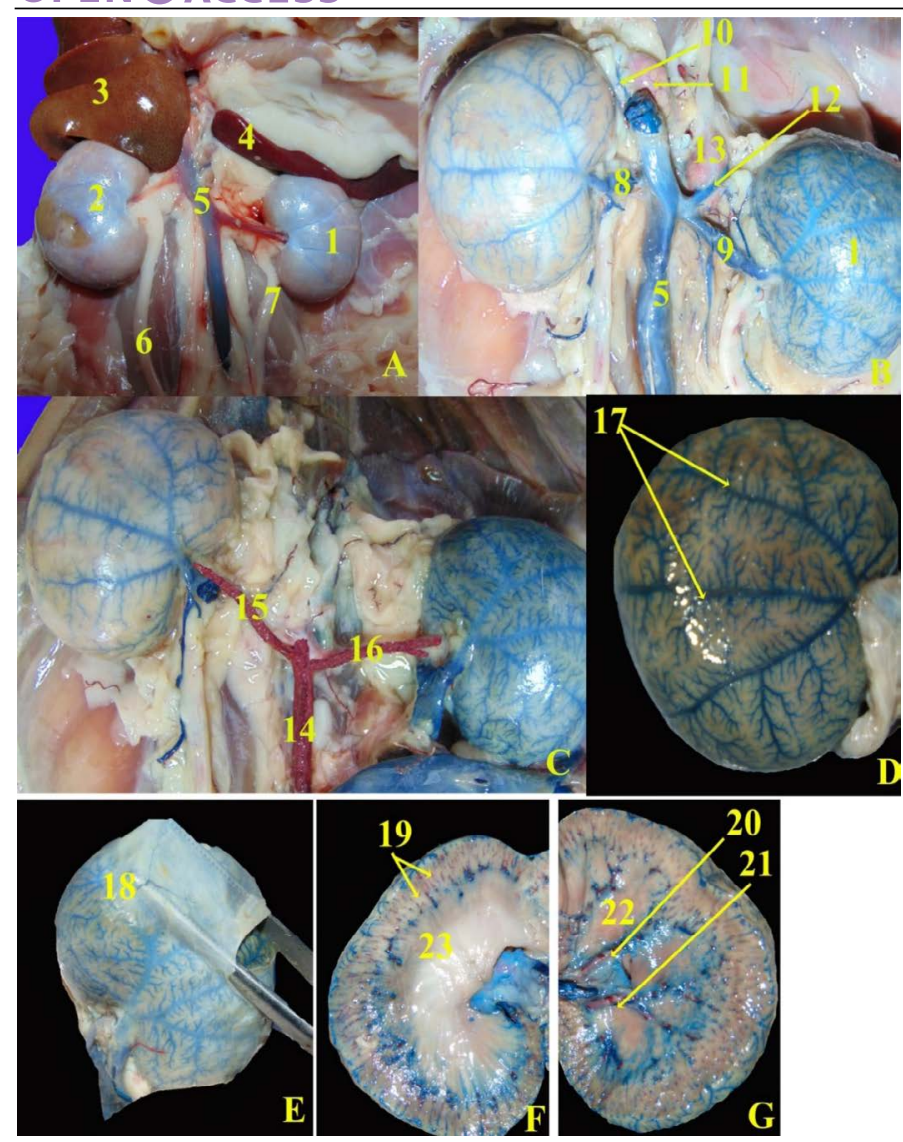

Figure 5: Anatomical magnified of the ventrodorsal view of the abdominal cavity of domestic healthy cat. A, Fresh specimen; B and C, Fresh specimen injected with blue and red latex neoprene; $\mathrm{D}$, refleccted renal capsule (dorsal surface of right kidney); $\mathrm{E}$, showing the content of fibrous capsule; F, midsagittal section; F, sagittal section. 1, left kidney; 2, right kidney; 3, caudate lobe of liver; 4, spleen; 5 , caudal vena cava; 6 , right ureter; 7 , left ureter; 8 , right renal vein; 9, left renal vein; 10 , right adrenal vein; 11 , right adrenal gland; 12, left adrenal vein; 13, left adrenal gland; 14, abdominal aorta; 15 , right renal artery; 16 , left renal artery; 17 , subcapsular veins; 18 , capsular veins; 19 , interlobular arteries; 20, interlobar artery; 21, interlobar viens; 22 , renal pyramid.

Regarding hematobiochemical alterations, the present study showed significant microcytic-hypochromic anemia with a reduction in $\mathrm{PCV}, \mathrm{Hb}$, and $\mathrm{RBC}$ s count in diseased cats. Similar findings were recorded by Mesquita et al. (2015). This can be explained by renal tissue damage made by a severely distended renal pelvis that put the case in the same situation as the chronic kidney injury. Present work revealed a significant increase in leucocytic and absolute neutrophilic counts in diseased cats which agreed with the findings of Snyder et al. (2005). It could be scrutinized that anemia and inflammatory process were linked in cats with unilateral Hydronephrosis as pyelonephritis was a consequence from destructive irritation made by stagnant urine at the renal pelvis. Serum biochemical results in diseased cats showed significant elevation of BUN and creatinine. These findings matched that of Lee et al. (2014) and Shipov and Segev (2013) as ureteral obstruction was a commonly recorded cause for acute uremia in cats. Another study described by Meldrum (2016) reviewed that decreased blood flow to the Hydronephrotic kidney resulted in decrease glomerular filtration and eventually acute kidney injury. The present result among serum creatinine was disagreed by Ragni and Fews (2008) who recorded normal creatinine levels in cases with unilateral Hydronephrosis. This may be due to the degree of severity of renal tissue damage. Also, severe hydraulic pressure made on the renal pelvis and cortex led to the loss of Bauman's capsule space and cessation of filtration. Another reason that renal parenchymal function loss made the future recovery of the affected kidney poor which resulted in rising creatinine levels.

Radiographic examination in the present study revealed the presence of radio-opaque renal calculi with marked enlargement of the kidney. These findings came in agreement with (Ragni and Fews, 2008). In some cases, urinary calculi in cats may be very small that could not be detected via radiographic examination (Clarke, 2018).

Regarding the hereinbefore results of ultrasonographical examination (Table 2), these findings were close to that of Huynh and Berry (2017) as the widely accepted normal ultrasonographic measurement of feline kidney varies between 3 and $4.3 \mathrm{~cm}$ in length. The renal capsule was a thin linear hyperechoic structure. Normal renal cortex was usually slightly hypo- or isoechoic when compared with the liver parenchyma and hypoechoic when compared with the splenic parenchyma. The renal medulla surrounded the renal pelvis was very hypoechoic to anechoic. Debruyn et al. (2012) agreed with the present study in the description of Hydronephrosis as it was a dilation of the renal pelvis and presence of several diverticula with the accumulation of anechoic fluid in the renal pelvis. In severe cases, progressive compression of the surrounding renal parenchyma resulted in cortical atrophy, and only a small rim of cortical tissue surrounding the dilated pelvis was noticed.

Our anatomical study revealed that kidneys were sublumbar and caudal to the rib cage and the anterior pole of the right kidney was related to the caudate lobe of the liver, also the left kidney was caudal to the spleen which was in agreement with (Debruyn et al.,2012). Kidneys of cats were small bean shaped, which was in agreement with Aspinall (2004), on contrast, Seiler (2018) gathered that they were round or oval, moreover, Huynh and Berry (2017) stated that they were oval-shaped. Similar to the observations of Aronson (2013), who stated that the kidneys were nearly mobile. Kidneys were light brownwhile, Aspinall (2004) mentioned that kidney of cat was reddish brown. 
In agreement with Aspinall (2004) and Seiler (2018), the kidneys extended ventral to $\mathrm{L} 2-\mathrm{L} 4$, and the right kidney situated more cranial than the left one, also they may be overlapping each other. The right kidney extended ventral to L2 -L4, in contrast, Aronson (2013) mentioned that it was ventral to L1-L4. The left kidney extended from L3L4, in the contrary, Aronson (2013) documented that the left kidney was situated at L2-L5.

The healthy kidney of the cat was 3 times the length of L2 which was in agreement with Farrow (2003) and Seiler (2018) and Aronson (2013) while the hydronephrotic kidney in our study reached 3.5 the length of L2 in contrary to Seiler (2018) who documented that normal cats may have larger kidneys from 2.1 to 3.2 times the length of $\mathrm{L} 2$.

Renal anatomical measurements in this study were in conjunction with Huynh and Berry (2017) and Miyabayashi (2001). While Maurya et al. (2018) documented that Cat's right kidney length in $\mathrm{cm} 3.83 \pm 0.46$ and left kidney length $3.82 \pm 0.32$. Our study as well as Aspinall (2004) revealed that a capsule encircling by fat was easily trimmed in the normal one. Similar to the observations of Aronson (2013) and Haschek et al. (2010) that the kidney of the cat was unipapillary and have venous drainage, without parallel arteries, of subcapsular parenchyma, with veins on the surface in addition to veins in the capsule, while those of the dog are subcapsular.

\section{CONCLUSIONS AND RECOMMENDATIONS}

We concluded that in some cases of unilateral hydronephrosis the measurements of the kidneywere normal but there was the loss of architecture of renal parenchyma ultrasonographically and after surgical nephrectomy of the affected kidney we found anatomically an increase in renal pelvis width with a normal length of the kidney. Also, in other cases the renal pelvis was mostly affected in the hydronephrotic kidney to be extremely dilated at the expense of the renal cortex and medulla thickness to reach in progressive stages to be membranous kidney from extreme enlargement. In addition to, significant changes in biochemical parameters were detected where significant $(\mathrm{P} \leq 0.001)$ increase in BUN level and significant increase $(\mathrm{P} \leq 0.01)$ in serum creatinine level.

\section{NOVELTY STATEMENT}

We viewed different finding in unilateral hydronephrosis which was different than the previous studies as the measurements of kidney were normal but there was the loss of architecture of renal parenchyma ultrasonographically and after surgical nephrectomy of the affected kidney we found anatomically an increase in renal pelvis width with normal length of the kidney. Also, the comparison between the healthy and hydronephrotic kidneys in their shape and positions and internal structure variations were illustrated.

\section{AUTHOR'S CONTRIBUTION}

Hitham Abdel-Saeed and Mohamed El Saeed Ali had performed the diagnostic study on unilateral hydronephrosis in domestic cats, and Reem Rashad Tahon had carried out the anatomical study on healthy and hydronerphrotic kidneys in cats.

\section{CONFLICT OF INTEREST}

The authors have declared no conflict of interest.

\section{REFERENCES}

-Abdel-Saeed H, Reem RT, Farag HS (2020). Diagnostic and epidemiological studies on obstructive feline lower urinary tract disease (FLUTD) with special reference to anatomical findings in Egyptian tomcats. Bulg. J. Vet. Med., (online first).

-Aronson LR (2013). Kidney and ureter, feline soft tissue and general surgery E-Book, pp. 401.

-Aspinall V (2004). Anatomy and physiology of the dog and cat. Urin. Syst. Vet. Nurs. J., 19(4): 130-135.

- Clarke DL (2018). Feline ureteral obstructions Part 1: Medical management. J. Small Anim. Pract., 59(6): 324-333.

- Debruyn K, Haers H, Combes A, Paepe D, Peremans K, Vanderperren K, Saunders JH (2012). Ultrasonography of the feline kidney: Technique, anatomy and changes associated with disease. J. Feline Med. Surgery 14(11): 794803.

- Farrow C (2003). Fundamentals of toxicologic pathology, Chapter 70, $2^{\text {nd }}$ Ed, Wanda M Haschek, Colin G Rousseaux and Matthew A Wallig. Academic Press.

-Haschek WM, Rousseaux CG, Wallig MA (2010). Kidney and lower urinary tract. Fundamentals of toxicologic pathology. $2^{\text {nd }}$ edn. Academic Press, chapter 11: 268.

-Huynh E, Berry CR (2017). Ultrasonography of the urinary tract: kidneys and ureters. Today's Vet. Pract., 7(6): 31-45.

- Lee N, Choi M, Keh S, Oh Y, Seo J, Choi H, Yoon J (2014). Bilateral congenital ureteral strictures in a young cat. Can. Vet. J., 55(9): 841.

- Levesque R (2007). SPSS programing and data management, $4^{\text {th }} \mathrm{Ed}$, SPSS Inc. USA.

- Maurya H, Kumar T, Kumar S (2018). Anatomical and physiological similarities of kidney in different experimental animals used for basic studies. J. Clin. Exp. Nephrol., 3(09). https://doi.org/10.21767/2472-5056.100060

-Meldrum K (2016).Pathophysiology of urinary tract obstruction. In: Campbell-Walsh Urology. (Wein A, Kavoussi L, Partin A). Elsevier, Philadelphia, PA, USA. pp. 1089-1103.

- Mesquita LR, Rahal SC, Matsubara L, Mamprim, MJ, Foschini CR, Faria LG, Kano WT (2015). Bilateral hydronephrosis and hydroureter after ovariohysterectomy using nylon cable tie: A case report. Vet. Med., 60(1): 52-56.

-Miyabayashi T (2001). Urogenital ultrasound, World small 
animal veterinary association world congress proceedings, Japan.

- Ragni RA, Fews D (2008). Ureteral obstruction and hydronephrosis in a cat associated with retroperitoneal infarction. J. Feline Med. Surg., 10(3): 259-263.

- Segev G (2011). Diseases of the ureter. In: Nephrology and urology of small animals. Ames, Iowa: Wiley-Blackwell. pp. 583-590.

- Seiler GS (2018). Textbook of veterinary diagnostic radiology,
Kidneys and ureters. WB Saunders. Chapter: 41, pp. 823845.

-Shipov A, Segev G (2013). Ureteral obstruction in dogs and cats. Israel J. Vet. Med., 68(2): 71-77.

- Snyder DM, Steffey MA, Mehler SJ, Drobatz KJ, Aronson LR (2005). Diagnosis and surgical management of ureteral calculi in dogs: 16 cases (1990-2003). N. Z. Vet. J., 53: 1925. 